\title{
The tonicity of murine epididymal spermatozoa and their permeability towards common cryoprotectants and epididymal osmolytes
}

\author{
T G Cooper ${ }^{1}$, J P Barfield ${ }^{1,2}$ and C H Yeung ${ }^{1}$ \\ ${ }^{1}$ Institute of Reproductive Medicine of the University, Domagkstrasse 11, D-48129 Münster, Germany and \\ ${ }^{2}$ Department of Biological Sciences, University of New Orleans, New Orleans, Louisiana, USA \\ Correspondence should be addressed to T G Cooper; Email: trevorg.cooper@ukmuenster.de \\ J P Barfield is now at the Department of Biomedical Sciences, Colorado State University, Fort Collins, Colorado, USA
}

\begin{abstract}
The permeability of murine cauda epididymidal spermatozoa was determined from the swelling caused by penetrating agents at isotonicity, which lies between 422 and $530 \mathrm{mmol} / \mathrm{kg}$. Spermatozoa were permeable to a range of solutes with size $<200 \mathrm{Da}$. Relative entry rates of cryoprotective agents (CPAs) were ethylene glycol $\approx$ DMSO $>$ propane-1,2-diol $>$ glycerol $>$ propane-1,3-diol. More polar compounds including major epididymal secretions were impermeant. None of the compounds entered spermatozoa through quininesensitive channels; rather, quinine increased the size of solute-swollen spermatozoa, suggesting that regulatory volume decrease and osmolyte loss occurred under these conditions. Volume responses to lowered osmolality revealed a greater volume-regulating ability of spermatozoa from the B6D2F1 strain than the C57BL6 strain. As the former strain displays better post-thaw fertility, their spermatozoa may have greater osmolyte loads enabling them to cope better with osmotic stress. Inadequate volume regulation, due to CPA-induced osmolyte loss, may affect post-thaw fertility. Knowing the permeability towards cryoprotectants will help to make a better choice of CPAs that are less damaging to sperm during cryopreservation.
\end{abstract}

Reproduction (2008) 135 625-633

\section{Introduction}

\section{Volume regulation by spermatozoa}

The ability of spermatozoa to regulate their volume is an integral part of their life within the reproductive tract of the male (where increasing osmolality is experienced from testis to distal epididymis; Cooper \& Yeung 2003) and the female (where lower osmolality than in the distal male tract exists; Cooper \& Barfield 2006). In the mouse, this difference in osmolality approximates $100 \mathrm{mmol} / \mathrm{kg}$ (Yeung et al. 1999, 2000) and would lead to cell swelling unless countered by regulatory volume decrease (RVD). RVD is an important event because when volume adjustments are inadequate, infertility may result (Cooper et al. 2004). The mechanisms of volume increase and decrease regulating this process involve the efflux and influx through membrane channels or transporters of low molecular weight, water-soluble compounds that counteract the osmotic movement of water driven by extracellular osmotic challenge.

These channels are being studied in several species in order to understand male infertility, design new contraceptives and improve cryopreservation protocols (Cooper
\& Barfield 2006), since spermatozoa suffer further alterations in volume after the removal from the male tract. Volume changes occur during an addition of cryoprotective agents (CPAs) depending on the relative permeability of the membrane to CPA and water. The most widely used CPA, glycerol (GLY), is slightly less permeant than water, so that cells initially shrink in the hypertonic medium and then swell as GLYand water enter the cell; this occurs in both human and murine spermatozoa (Gao et al. 1995, Agca et al. 2002). During the freezing process, increased extracellular osmolality tends to dehydrate the cell; this is reversed upon thawing and further exacerbated when the extracellular CPA is removed and water enters the CPA-laden cell (Gao et al. 1997).

\section{Osmolyte load and loss during volume regulation}

It is possible that the volume regulatory process invoked by these osmolality changes depletes the cells of osmolytes long before they are needed for size maintenance during subsequent insemination and this could compromise post-thaw fertility. Spermatozoa with lower 
osmolyte content would suffer more from osmolyte loss than those with larger osmolyte reserves, and the latter would better cope with osmotic stresses experienced during insemination. In this way, the efficiency of volume regulation could underlie the well-established differences in cryodamage to spermatozoa observed in different strains of mice (Songsasen \& Leibo 1997) and between different individual men (McLaughlin et al. 1992, Leibo et al. 2002), dogs (Yu et al. 2002) and other species (Leibo \& Bradley 1999). If this were so, the volume regulatory response of spermatozoa from strains of mice displaying good post-thaw fertility may be better than that of strains exhibiting poor post-thaw fertility.

To improve cryopreservation and minimise such volume disruption, the addition and removal of CPA in sequential steps (Gao et al. 1995, Phelps et al. 1999, Agca et al. 2002) and the simultaneous addition of nonpenetrating CPAs (Agca et al. 2002) have been suggested. Another approach would be to employ CPAs that have a closer permeability to that of water in order to avoid large volume changes. This approach is likely to need speciesspecific tailoring as spermatozoa from different strains of mice vary in CPA penetration (Agca et al. 2002) and osmotic tolerance (Walters et al. 2005). Knowledge of sperm permeability towards putative cryoprotectants could help optimise cryopreservation procedures, since high penetration of solutes (cryoprotectants) could lead to cell swelling and induce RVD driven by the loss of osmolytes. Such osmolyte loss compromises post-thaw sperm volume regulation upon insemination. Knowledge of the uptake of osmolytes into spermatozoa could help define less damaging cryoprotectants or establish conditions whereby osmolytes could be replaced during unavoidable cell volume changes.

\section{Permeability of spermatozoa}

The permeability of spermatozoa to a variety of low molecular weight soluble compounds was first examined by Drevius (1971, 1972), in which spermolysis and spermatocrit measurements were taken as indices of the swelling of bovine epididymal spermatozoa. These studies were done at the osmolality of epididymal fluid (c. $353 \mathrm{mmol} / \mathrm{kg}$ ) where swelling reflects the permeability of the unstressed membrane of the non-swollen cell to the compounds added at high concentration that enter the cell drawing water with them. Osmolyte entry into bovine ejaculated spermatozoa was proposed to be via quininesensitive channels (Kulkarni et al. 1997). Such extensive studies have not been done in the mouse but Agca et al. (2002) found that penetrating cryoprotectants induced 'non-linear' flagellar forms (angulated swollen spermatozoa; Yeung et al. 2002a).

Many studies on murine epididymal spermatozoa have described them as ideal osmometers with isotonicity being assumed to be around 286, 290 or $300 \mathrm{mmol} / \mathrm{kg}$ (Du et al. 1994, Noiles et al. 1995, 1997, Willoughby et al. 1996, Agca et al. 2002, Walters et al. 2005). However, several observations argue against this contention: (i) these values are nowhere near the reported osmolality of epididymal fluid, some $100 \mathrm{mmol} / \mathrm{kg}$ higher (see Cooper \& Barfield 2006); (ii) transfer of distal cauda epididymidal spermatozoa to media of c. $300 \mathrm{mmol} / \mathrm{kg}$ induces swelling (Yeung et al. 2002a) which, by definition, does not occur in isotonic media; (iii) volume-regulating cells cannot be described as ideal osmometers since they are not responding passively to, but resisting, the osmotic challenge; and (iv) the linear relationship between cell volume and extracellular osmolality deviates around physiological values (Du et al. 1994) as anticipated when RVD is occurring. Thus, the tonicity of epididymal spermatozoa has to be established first before isotonic swelling in the presence of penetrating solutes can be used to estimate the differential permeability of the sperm membrane. It is hypothesised that the tonicity of murine cauda epididymidal spermatozoa lies close to the osmolality of epididymal fluid and not that of the female tract.

In summary, spermatozoa that are swollen as a result of failed volume regulation suffer disadvantages in natural fertilisation, most likely as a result of reduced osmolyte content (Yeung et al. 2004). The fact that commonly used CPAs cause sperm swelling suggests that there may have been osmolyte loss as a result of RVD. As cryopreservation may benefit from the use of CPAs causing less change in cell volume, methods for determining CPA permeation into spermatozoa and estimating osmolyte load are required. This work tests the hypotheses that (i) the tonicity of murine epididymal spermatozoa is close to that of epididymal fluid and (ii) spermatozoa from strains of mice with poor post-thaw fertility have spermatozoa that regulate their volume poorly. The value determined for sperm tonicity was used to monitor CPA penetration in spermatozoa at isotonicity. These procedures could be used on spermatozoa from other species and the results used to select less disruptive CPAs.

\section{Results}

\section{The tonicity of murine cauda epididymidal spermatozoa}

At $75 \mathrm{~min}$, the extent of swelling in hypotonic medium induced by quinine depended on the nature of the medium and was always higher in high ionic strength media (in $\mathrm{NaCl}$ and choline $\mathrm{Cl}$ ) than in low ionic strength media (sucrose and lactose). As the osmolality increased, the difference in size between quinine-treated and -untreated spermatozoa (reflecting the extent of volume regulation) decreased for all osmolytes (Fig. 1). There was no significant difference between this measure of volume regulation and zero (i.e. no volume regulation was occurring, indicating a state of isotonicity) when the osmolality reached $528 \mathrm{mmol} / \mathrm{kg}$ for a medium containing $\mathrm{NaCl}, 462 \mathrm{mmol} / \mathrm{kg}$ for choline $\mathrm{Cl}, 458 \mathrm{mmol} / \mathrm{kg}$ 


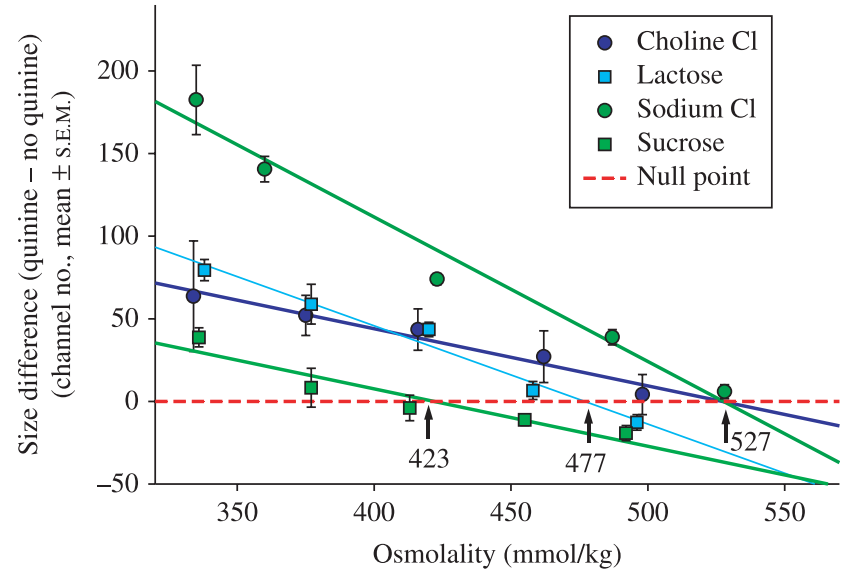

Figure 1 The RVD response of murine cauda epididymidal spermatozoa (size difference in the presence and absence of quinine: ordinate) as a function of extracellular osmolality (abscissa). Linear regression lines $\left(y=b_{0}+b_{1} x\right)$ are solid and regression equations were, for media containing largely choline $\mathrm{Cl}$ (dark blue circles): $b_{0} 182, b_{1}-0.3462$, $r^{2}$ 0.957; lactose (light blue squares): $b_{0} 284, b_{1}-0.595, r^{2} 0.978$; $\mathrm{NaCl}$ (dark green circles): $b_{0} 461, b_{1}-0.874, r^{2} 0.972$; sucrose (light green squares): $b_{0} 147, b_{1}-0.347, r^{2} 0.898$. Arrows indicate null point $(\mathrm{mmol} / \mathrm{kg})$. Values are mean \pm s.E.M., $n=4$.

for lactose but was far lower $(377 \mathrm{mmol} / \mathrm{kg}$ ) for sucrosecontaining medium. Linear regression analysis revealed the null point to be $527 \mathrm{mmol} / \mathrm{kg}$ for both $\mathrm{NaCl}^{-}$and choline $\mathrm{Cl}^{-}, 477 \mathrm{mmol} / \mathrm{kg}$ for lactose- and $423 \mathrm{mmol} / \mathrm{kg}$ for sucrose-containing media. In the presence of sucrose, the difference in size of quinine-treated and -untreated spermatozoa was significantly smaller than zero at 455 and $492 \mathrm{mmol} / \mathrm{kg}$.

\section{Membrane permeability at isotonicity}

As the null point was dependent on both charge and osmolality, and the osmolytes to be tested were both uncharged polyols and charged amino acids, the higher tonicity medium $(530 \mathrm{mmol} / \mathrm{kg}$ ) was taken as isotonic for these studies. This reduces the possibility that osmotic swelling, and the concomitant opening of volumesensitive channels, would complicate the interpretation of permeability. As the performance of RVD in response to cell swelling would reduce the size of the cells, only data from swelling that occurred in the presence of solutes and quinine are presented.

The mean size of spermatozoa at isotonicity in the presence of all six impermeant sugars $(>340 \mathrm{~d}$ : the trisaccharide raffinose $\left(C_{18}\right)$ and disaccharides $\left(C_{12}\right)$ sucrose, trehalose, lactose, melibiose and maltose at $250 \mathrm{mM}$ ), as assessed from the mean channel number (CN), was 332 . The upper $95 \%$ confidence limit of the size of these spermatozoa (367 CN) was taken as the size threshold below which compounds were considered to be non-penetrating (Fig. 2). Most compounds <200 Da were thus considered penetrating as they induced cell volume

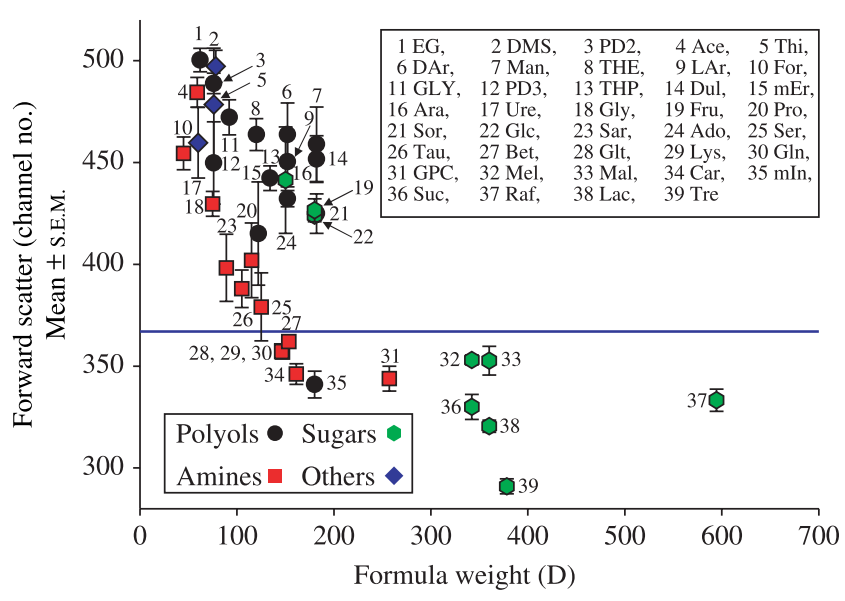

Figure 2 Size of murine spermatozoa (ordinate) after incubation in isotonic medium containing $250 \mathrm{mM}$ compounds of differing molecular weight (abscissa) and different functional groups (polyols (black circles), sugars (green hexagons), amines (red squares) and others (blue diamonds)).

Numbers by symbols refer to the abbreviations in the inset: Ace, acetamide; Ado, adonitol; Ara, arabinose; Bet, betaine; Car, L-carnitine; DAr, D-arabitol; DMS, dimethyl sulphoxide; Dul, dulcitol; EG, ethylene glycol; THP, 1,1,1tris(hydroxymethyl)propane; For, formamide; Fru, fructose; Glc, glucose; Gln, glutamine; Glt, glutamate $\left(\mathrm{K}^{+}\right.$and $\mathrm{Na}^{+}$salts); Gly, glycine; GLY, glycerol; GPC, glycerophosphocholine; lac, lactose; LAr, L-arabitol; Lys, lysine; Mal, maltose; Man, mannitol; Mel, melibiose; $\mathrm{mEr}$, meso-erythritol; mln, myo-inositol; Pro, proline; PD2, propane-1,2-diol; PD3, propane-1,3diol; Sor, sorbitol; THE, 1,1,1-tris(hydroxymethyl)ethane; Raf, raffinose; Sar, sarcosine; Ser, serine; Suc, sucrose; Tau, taurine; Thi, thiourea; Tre, trehalose; Ure, urea. Values are mean \pm S.E.M., $n=6$ except for trehalose $(n=4)$, fructose, dulcitol, THE, DMSO, EG $(n=5)$ and quinine $(n=72)$.

increase above this threshold, indicating that osmotic entry of water followed their permeation into the cell. The extent of entry was independent of the nature of the compound as both uncharged and charged polyols, sugars and amines all caused swelling. Overall, the polyols penetrated to a greater extent than the amines (Fig. 2). Several polar compounds, glycerophosphocholine (GPC), myo-inositol, L-carnitine, glutamate, glutamine, betaine and lysine were considered impermeant by this criterion (Fig. 2). Of the common CPAs relative order of penetrability was EG $>$ DMS $>$ PD2 $>$ GLY $>$ THE $>$ PD3 $>$ THP for C57BL6 mice (see Fig. 2 legend for full names).

There was no relationship of the extent of swelling to the number of hydroxyl groups or the polarity of the compounds as defined by the $\mathrm{C} / \mathrm{OH}$ ratio (Storey et al. 1998) or the mean molecular cylindrical radius, as measured from molecular modelling (Strange \& Jackson 1995) or calculated from a formula (Tsukaguchi et al. 1998) (data not shown).

The presence of quinine did not reduce the entry of any permeant compound into spermatozoa and in fact significantly larger volumes were achieved in the presence of quinine for most compounds tested. Figure 3 shows the consistently larger volumes in the presence of quinine. Overall, the greater the cell size induced by permeating solutes, the greater the effect of quinine. 


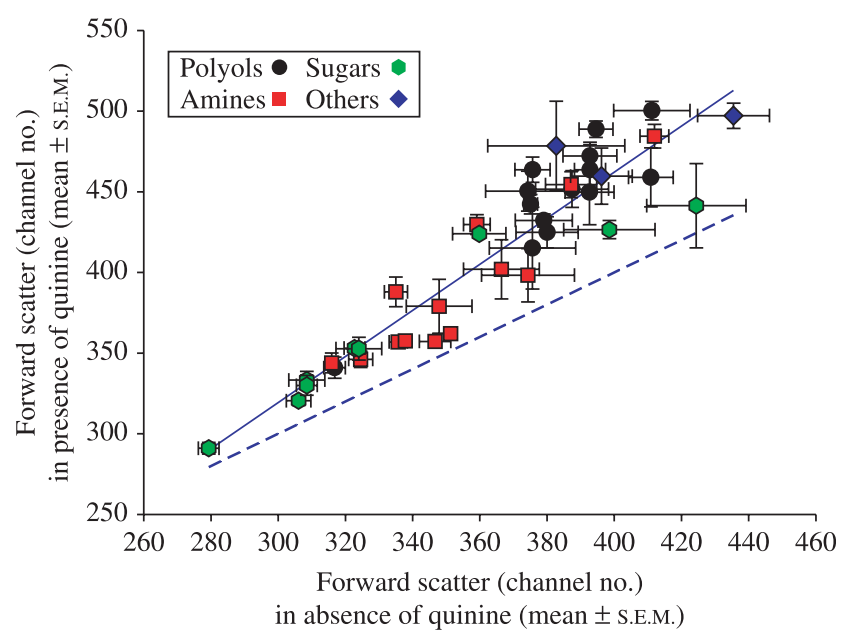

Figure 3 Size of murine spermatozoa in the absence (abscissa) and presence (ordinate) of $0.8 \mathrm{mM}$ quinine $\mathrm{HCl}$. Solid blue line, line of regression; dotted blue line, line of identity. Values are mean \pm s.E.M.; for $n$ values, see Fig. 2. Polyols (black circles), sugars (green hexagons), amines (red squares), others (blue diamonds).

\section{Osmolyte load of cauda epididymidal spermatozoa from two mouse strains differing in post-thaw fertility}

Extent of volume regulation with decreasing osmolality in high ionic strength $(\mathrm{NaCl})$ medium

As isotonicity in $\mathrm{NaCl}$ medium was measured to be $527 \mathrm{mmol} / \mathrm{kg}$ (see above), the medium of $530 \mathrm{mmol} / \mathrm{kg}$ was assumed to be isotonic. At this osmolality the volume of spermatozoa of neither strain changed much with time and there was no difference between strains (Fig. 4a). At all lower osmolalities, the cell volume measured after $120 \mathrm{~min}$ was larger in the order $160 \leq 245>330>$ $530 \mathrm{mmol} / \mathrm{kg} \min$ (Fig. 4a and b) although after $15 \mathrm{~min}$ the order was $330>245>160 \gg 530 \mathrm{mmol} / \mathrm{kg}$. With a physiological challenge $(330 \mathrm{mmol} / \mathrm{kg}$ (Yeung et al. 2000), i.e. providing an osmotic challenge of $200 \mathrm{mmol} / \mathrm{kg}$, spermatozoa were observed to swell between 15 and $30 \mathrm{~min}$ and then return to the 15 -min volume by $60 \mathrm{~min}$ and continue to decrease volume thereafter. B6D2F1 spermatozoa were consistently and significantly smaller than C57BL6 at all time points in a medium of $330 \mathrm{mmol} / \mathrm{kg}$ (Fig. 4a). At $245 \mathrm{mmol} / \mathrm{kg}$ (an osmotic stress of $285 \mathrm{mmol} / \mathrm{kg}$ ) spermatozoa continued to swell throughout the incubation but at $160 \mathrm{mmol} / \mathrm{kg}$ (a $370 \mathrm{mmol} / \mathrm{kg}$ insult) cell volumes were first maintained between 15 and 30 min before unregulated volume increase was observed. At the latter osmolality, B6D2F1 strain spermatozoa were consistently and significantly smaller than those of the C57BL6 strain (Fig. 4b).

\section{Chloride dependence of volume regulation in Na-gluconate medium}

Although it was anticipated that cell volumes would be the largest at the lowest osmolality tested, this was not the case (Fig. 4b). As the lowest osmolality of $\mathrm{NaCl}$ medium tested was obtained at the expense of lower $\mathrm{Cl}^{-}$, $\mathrm{Na}^{+}$and ionic strength (Table 2), factors other than $\mathrm{Na}^{+}$ may be influencing osmotic response at such low
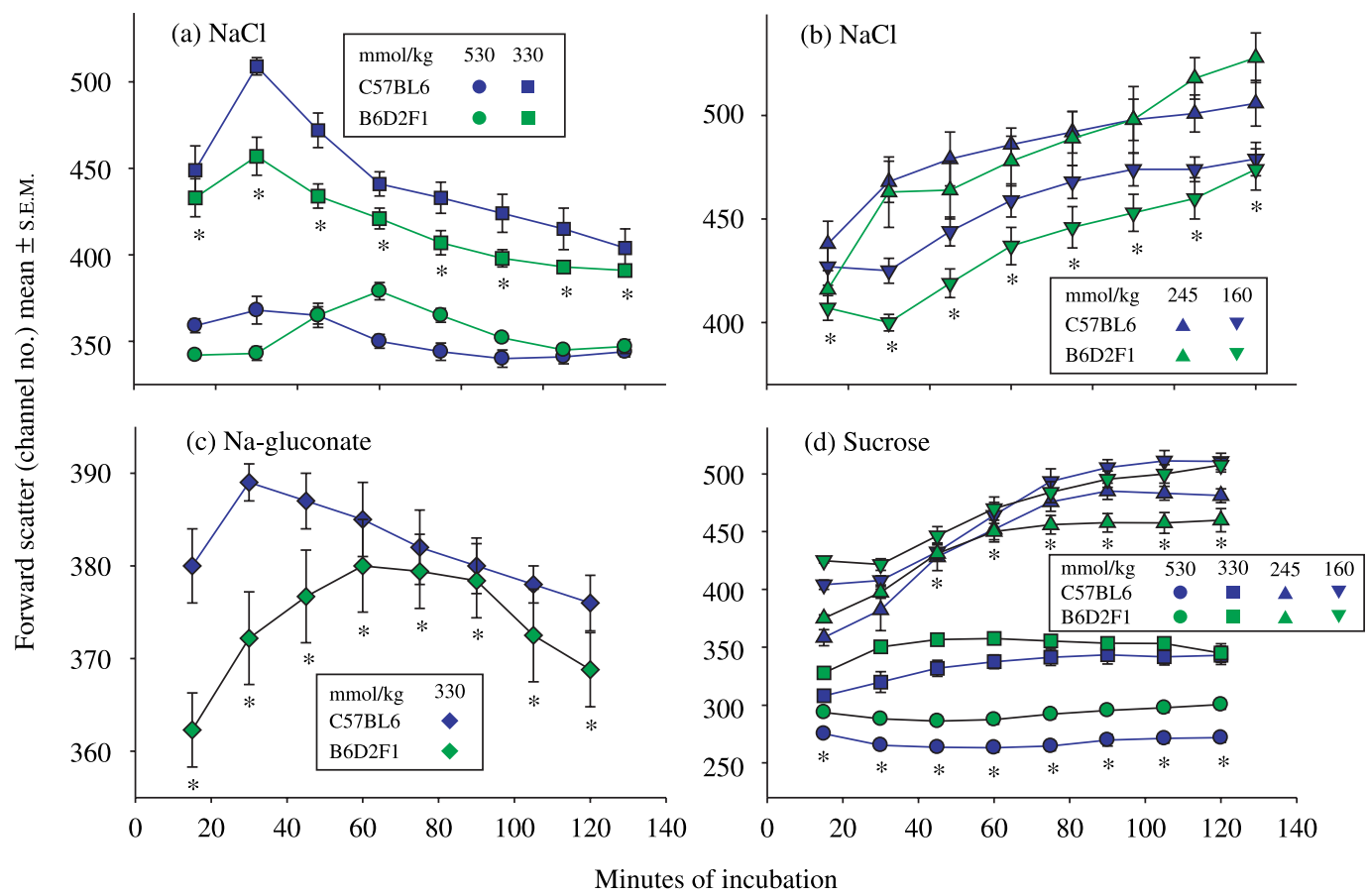

Figure 4 Size (ordinate) of murine spermatozoa (C57BL6 strain, blue symbols; B6D2F1 strain, green symbols) with time (abscissa) in media containing (a and b) NaCl, (c) Na-gluconate and (d) sucrose and of differing osmolality (mmol/kg: 530 (circles), 330 (squares), 245 (up triangles), 160 (down triangles). Diamonds in (c) $15 \mathrm{mM} \mathrm{Cl}^{-}$in Na-gluconate, $300 \mathrm{mmol} / \mathrm{kg}$. Values are mean \pm s.E.M., $n=6$. *Significantly different between strains. 
osmolality. For example, the greater concentration difference for $\mathrm{Cl}^{-}$at the lower tonicity may promote $\mathrm{K}^{+}$ efflux and RVD. In order to check this possibility, media of $330 \mathrm{mmol} / \mathrm{kg}$ and constant $\mathrm{Na}^{+}$and ionic strength were made by replacing $\mathrm{Cl}^{-}$with gluconate. Cell volumes were indeed smaller with lower concentrations of $\mathrm{Cl}^{-}$ (size in $15<28<58 \mathrm{mM} \mathrm{Cl}^{-}$) and at $15 \mathrm{mM} \mathrm{Cl}^{-}$ spermatozoa from the B6D2F1 strain were significantly smaller than those of the C57BL6 strain (Fig. 4c).

\section{Greater volume regulation in low ionic strength (sucrose) medium}

When sucrose was used to raise the osmolality, the highest osmolality tested $(530 \mathrm{mmol} / \mathrm{kg}$ ) was hypertonic (by about $100 \mathrm{mmol} / \mathrm{kg}$ ) to the $422 \mathrm{mmol} / \mathrm{kg}$ that was determined to be iso-osmotic for spermatozoa in this medium (see above). The forward scatter measured in $530 \mathrm{mmol} / \mathrm{kg}$ was far lower than that obtained in $\mathrm{NaCl}$ and no changes with time were observed. Throughout the incubation at $530 \mathrm{mmol} / \mathrm{kg}$ spermatozoa from the C57BL6 strain were significantly smaller than those of the B6D2F1 strain (Fig. 4d). Sperm sizes at the other osmolalities were also smaller than those determined in $\mathrm{NaCl}$ medium but in the following order: 160>245> $330>530 \mathrm{mmol} / \mathrm{kg}$. Little volume change in spermatozoa from either strain was observed in a medium of $330 \mathrm{mmol} / \mathrm{kg}$ that provided a hypotonic osmotic insult of only $100 \mathrm{mmol} / \mathrm{kg}$. When osmolality was lowered to $245 \mathrm{mmol} / \mathrm{kg}$ (an osmotic challenge of about $185 \mathrm{mmol} / \mathrm{kg}$ ), volume gradually increased over $60 \mathrm{~min}$ and at $160 \mathrm{mmol} / \mathrm{kg}$ (a $270 \mathrm{mmol} / \mathrm{kg}$ challenge) spermatozoa from both strains were able to maintain a moderate volume from 15 to 30 min before this capacity was lost and a plateau value was reached (Fig. 4d). During this early period at $160 \mathrm{mmol} / \mathrm{kg}$, spermatozoa from the B6D2F1 strain were significantly smaller than those from the C57BL6 strain.

\section{Discussion}

Osmolyte influx and efflux into spermatozoa depend on extracellular osmolality when volume-sensitive channels are activated. During volume regulation in hypotonic media osmolytes are lost from the cell, and any premature loss of osmolytes, such as during handling of cryopreservation, puts the cell at risk of being unable to regulate volume later, when it may be important. As swelling can also occur when cells are held at isotonicity as a result of penetrating solvents drawing in osmotically obliged water (Guizouarn \& Motais 1999), osmolyte loss may occur when CPAs enter spermatozoa during cryopreservation. This loss could be prevented, or osmolytes replaced, if more were known about the permeability of sperm membranes and the uptake of osmolytes into spermatozoa.

\section{Tonicity of epididymal spermatozoa}

Cytoplasmic osmolality can be determined when cells bathed in a medium have no need to respond osmotically. In this study, this was measured for spermatozoa from the cauda epididymidis by exposing them to the media of various osmolalities and taking the degree of cell swelling in the absence of volume regulation (in the presence of quinine as RVD blocker) to reflect the extent of osmotic water flux. The osmolality of the medium causing no swelling was taken to be the intracellular osmolality. As anticipated, spermatozoa swelled less in the presence of quinine as the extracellular osmolality was increased, but the extent of volume regulation depended on the nature of the medium. The value determined to be isotonic in high ionic strength media was far higher than the upper limits of the osmolality determined for cauda epididymidal fluid, but values in low ionic strength media were closer to the measured values (Cooper \& Barfield 2006). As the ionic strength of cauda epididymidal fluid is low (Cooper 1998), the lower values may reflect the true tonicity of epididymal spermatozoa in situ.

In low ionic strength media, swelling was also dependent on the nature of the non-reducing sugar present and was less extensive than that with high ionic strength solutions of sodium or choline. This could be indicating a better volume regulatory performance of spermatozoa in low ionic strength, low $\mathrm{Cl}^{-}$media or an entry into the cell of $\mathrm{NaCl}$ at the high concentrations, driving water influx and exaggerating cell swelling (there is evidence that permeation of ions at isotonicity increases intracellular ionic strength and activates RVD; Guizouarn \& Motais 1999). Irrespective of the mechanism, the ionic strength and the nature of the major extracellular compound responsible for raising the osmolality of the medium clearly can influence values obtained for intracellular tonicity.

Alteration in the ionic strength of the environment would affect the charge of the membrane and could alter the activity of pumps and channels directly or indirectly involved in ion fluxes across the membrane and thus modulate the extent of osmolyte movements. Indeed, extracellular ionic strength is known to modulate the effect of inhibitors of voltage-gated potassium channels (Knaus et al. 1995), and several studies have demonstrated that intracellular ionic strength induced by water influx alters the activity of volume-regulated anion channels (Nilius et al. 2000, Sabirov et al. 2000). The decrease in size of spermatozoa in a high concentration of sucrose was exaggerated in the presence of quinine, indicating that this drug inhibits regulatory volume increase (RVI) that should occur when the murine spermatozoa are dehydrated. Quinine can also partially prevent RVI in porcine spermatozoa (Petrunkina et al. 2005). 


\section{Permeability of spermatozoa to low molecular weight solutes}

Some, but not all, compounds with six or fewer carbon atoms $(<200$ D) penetrated spermatozoa enough to induce swelling. The permeability of murine spermatozoa to the polyols ( $\mathrm{D}$-arabitol $>$ mannitol $>$ dulcitol $>$ L-arabitol $>$ adonitol $>$ sorbitol $>m$-erythritol) contrasts with that of bovine epididymal spermatozoa ( $m$-erythritol $>$ adonitol $>$ D-arabitol $>$ sorbitol $>$ L-arabitol $=$ mannitol $=$ dulcitol; Drevius 1971). Mannitol and dulcitol were more penetrating than compounds of the same molecular size, which may indicate the presence of transporters in spermatozoa. Aquaporin 9 can mediate polyol transfer (Tsukaguchi etal. 1998) but there are no reports of AQP9 in spermatozoa. GLUT5, a facilitative glucose transporter that transports fructose (Joost \& Thorens 2001), is present in canine spermatozoa (Rigau et al. 2002).

Of the cryoprotectants tested, the extent of penetration was found to be $\mathrm{EG} \approx \mathrm{DMS}>\mathrm{PD} 2>\mathrm{GLY}>\mathrm{THE}>\mathrm{PD} 3>$ THP for spermatozoa from C57BL6 mice. Other volume measurements of murine spermatozoa have demonstrated a greater permeability at room temperature for EG than GLY for B6C3F1 and the ICR strain of mice (Agca et al. 2002) whereas Phelps et al. (1999) found the relative permeability $\mathrm{EG}>\mathrm{GLY}>\mathrm{PD} 2$ for ICR mice but GLY $>$ $\mathrm{EG}>\mathrm{PD} 2$ for spermatozoa from the B6C3F1 strain. The finding that tris(hydroxymethyl)-propane and -ethane were less penetrating agents than GLY implies that they should produce less swelling than GLY when they are added to spermatozoa and thus could improve post-thaw recovery, but they could increase the initial cell shrinkage. When added together with GLY, these compounds were deleterious to murine spermatozoa (Storey et al. 1998), but the effects of these agents added alone were not studied.

Surprisingly, many epididymal secretions (GPC, glutamate, L-carnitine and myo-inositol) did not cause an increase in size of spermatozoa above that of the impermeant di- and trisaccharides. It has been postulated that they are provided to spermatozoa in the epididymis (Cooper \& Yeung 2003) which would require them to be membrane permeant. Estimates of intracellular concentrations based on murine sperm volume (Willoughby et al. 1996) and osmolyte content (Yeung et al. 2004) indicate $33 \mathrm{mM}$ for L-carnitine and $38 \mathrm{mM}$ for myo-inositol, which confirm that a substantially higher intracellular concentration was applied in these experiments. The inability of the epididymal osmolytes to enter the cells under isotonic conditions could reflect their polarity: myo-inositol is uncharged but highly polar whereas L-carnitine and GPC are zwitterions with little charge at neutral $\mathrm{pH}$; GPC is also impermeant to renal cells (Zablocki et al. 1991). These results suggest that at isotonicity spermatozoa are impermeable to these secretions (i.e. channels are closed) and uptake of osmolytes must occur when volumesensitive channels are activated during hypertonic stress experienced within the epididymis (Cooper \& Yeung 2003).

\section{Volume regulation during swelling at isotonicity}

The inability of quinine to restrict the entry of osmolytes into murine spermatozoa at isotonicity contrasts with the contention of Kulkarni et al. (1997) who demonstrated that quinine blocked the swelling of bovine spermatozoa induced by high extracellular concentrations of some of the same compounds. The explanation could lie in different species but is more likely to reflect the use of ejaculated rather than epididymal spermatozoa and the osmotic changes incumbent in preparing these cells for study. Firstly, bovine seminal plasma has an osmolality $(\mathrm{mmol} / \mathrm{kg})$ of around 341-355 (Salisbury \& Cragle 1956, White \& MacLeod 1963, Verbeckmoes et al. 2001), but in the study of Kulkarni et al. (1997) spermatozoa were prepared by swim up in $0.15 \mathrm{M} \mathrm{NaCl}+5 \mathrm{mM} \mathrm{Na}$ phosphate $(\sim 310 \mathrm{mmol} / \mathrm{kg})$. This so-called isotonic medium was actually hypotonic since spermatozoa swelled in it in the presence of quinine. Thus, their osmolyte status may have been altered even before examination. Secondly, during the uptake experiments, spermatozoa were subjected to a hypertonic medium $(0.31 \mathrm{M}$ osmolytes $+35 \mathrm{mM} \mathrm{NaCl}+$ $5 \mathrm{mM} \mathrm{Na}$ phosphate or $\sim 390 \mathrm{mmol} / \mathrm{kg}$ ). Thus, the quinine sensitivity determined by Kulkarni et al. (1997) may be a characteristic of shrinkage-sensitive channels permitting osmolyte uptake during RVI.

The present results, demonstrating that quinine could increase further the volume of murine epididymal spermatozoa swollen in the presence of penetrating solutes, are compatible with the drug's ability to inhibit RVD driven by purely water-driven cell swelling (Yeung et al. 2002a, Barfield et al. 2005). The results also provide evidence that penetrating compounds, of which CPAs are prime examples, also activate RVD and thus are responsible for osmolyte loss, although the fact that the cells swelled indicates that RVD was not fully operational under these conditions. Furthermore, the fact that quinine had a greater effect (RVD was more effective) when the extent of swelling was greater suggests that the cells lose more osmolytes in the presence of the more penetrating solutes. This would explain the flagellar angulation displayed by bovine spermatozoa in the presence of GLY-containing CPAs that cause 'backwards swimming' (Phillips \& Kalay 1984). As such angulation can be the cause of natural infertility (Cooper \& Barfield 2006), this is a condition to be avoided during cryopreservation, the aim of which is to preserve, rather than hinder, the fertilising capacity of spermatozoa.

\section{Osmolyte load of spermatozoa from strains of mice with different post-thaw fertility}

Although the trends in volume regulation in anisotonic media were parallel in both mouse strains, spermatozoa from the B6D2F1 strain were consistently better at regulating volume than those from the C57BL6 strain. Whether the basis for this is a greater initial osmolyte reserve to call upon during hypotonic stress requires 
verification. Whatever the cause, their superior volumeregulating ability could, in part, contribute to the higher rates offertilisation initiated by B6D2F1 spermatozoa than C57BL6 spermatozoa after cryopreservation (Songsasen \& Leibo 1997). Screening of the osmolyte reserves in this way should be helpful in predicting post-thaw survival of spermatozoa from different species and detecting individual differences in potential cryodamage and provide a rationale for the choice of $\mathrm{CPA}$.

\section{Materials and Methods}

\section{Animals, collection and incubation of epididymal spermatozoa}

Adult mice of the C57BL6 and B6D2F1 strains (Charles River, Sulzfeld, Germany) about 70 days old were used for the retrieval of epididymal spermatozoa. Animals were kept in 12 light:12 darkness with free access to water and chow. They were killed by asphyxiation with $\mathrm{CO}_{2}$ followed by cervical dislocation. These experiments were conducted according to the German Federal Law on the Care and Use of Laboratory Animals (license no. G67/01). The testis-epididymis complex was dissected out, and the cauda epididymidis isolated and its capsule was removed. The tubule was uncoiled to expose the entire length of the mid and distal cauda. Lengths of the tubule were cut out and placed in separate $10 \mu \mathrm{l}$ drops on a plastic spatula of modified BiggersWhittingham-Whitten (BWW) medium (Biggers et al. 1971) of differing osmolalities or containing osmolytes. The order of osmolytes tested during the experiment was changed each time to ensure that the location of the spermatozoa within the cauda, and the time lapse between organ removal and sperm collection, did not confound the results. Spermatozoa were then gently expressed from the tubule with fine forceps and the tubule removed from the drop. The drop was then dispersed in $200 \mu \mathrm{l}$ of the same medium and the sperm suspensions placed in an incubator $\left(37^{\circ} \mathrm{C}, 5 \%(\mathrm{v} / \mathrm{v}) \mathrm{CO}_{2}\right.$ in air). After $\sim 2 \mathrm{~min}$, sperm suspensions were gently agitated and the incubation continued for up to $120 \mathrm{~min}$.

\section{Chemicals}

Chemicals (formula weight $(\mathrm{d}) /$ density $(\mathrm{g} / \mathrm{ml})$ ) were from Sigma-Aldrich. The following compounds were used: (i) cryoprotectants: dimethyl sulphoxide (78/1.1), EG (62/1.11), GLY (92/1.26), (S)-PD2 (76/1.01), PD3 (76/1.05), raffinose (595), sucrose (342), trehalose (378), THE (120) and THP (134); (ii) other compounds covering a wide range of molecular sizes: acetamide (59), adonitol (152), L-arabitol and D-arabitol (152), D-arabinose (150), betaine (154), Ddulcitol (182), meso-erythritol (122), formamide (45/1.13), fructose (180), glucose (180), glutamine (146), glycine $\mathrm{HCl}$ (75), lactose (360), L-lysine (146), maltose (360), D-mannitol (182), melibiose (342), L-proline (115), sarcosine (89), serine (105), thiourea (76) and urea (60); (iii) epididymal secretions that may be sperm osmolytes: L-carnitine $\mathrm{HCl}(161), \mathrm{Na}^{+}$ and $\mathrm{K}^{+}$glutamate (147), Cd-free glycerophosphocholine (257), myo-inositol (180), D-sorbitol (182) and taurine (125).

\section{Incubation media used}

To determine the tonicity of epididymal spermatozoa, they were incubated in media of osmolality extending around the values measured for epididymal fluid (400-480 mmol/kg; see Cooper \& Barfield 2006). These were based on BWW medium $\left(4.8 \mathrm{mM} \mathrm{KCl}, 1.7 \mathrm{mM} \mathrm{CaCl}_{2}, 1.2 \mathrm{mM} \mathrm{MgSO}_{4}, 1.2 \mathrm{mM}\right.$ $\mathrm{KH}_{2} \mathrm{PO}_{4}, 0.25 \mathrm{mM} \mathrm{Na}$ pyruvate, $5.5 \mathrm{mM}$ glucose, $26 \mathrm{mM} \mathrm{Na}$ lactate, $25 \mathrm{mM} \mathrm{NaHCO}$, $108 \mathrm{mM} \mathrm{NaCl}, 20 \mathrm{mM}$ HEPES (pH 7.4)) that was amended to include additional $\mathrm{NaCl}$, choline $\mathrm{Cl}$, sucrose or lactose. Osmolality was measured by vapour pressure osmometry (Wescor Vapro model 5520, Kreienbaum Messsystem, Langenfeld, Germany) and the final osmolalities and ionic strengths of these solutions are given in Table 1.

\section{Measurement of cell size by flow cytometry}

Changes in viable sperm cell volume were measured in a flow cytometer (Coulter Epics XL, version 3.0, Krefeld, Germany) according to the method established by Yeung et al. (2002b) in which a linear relationship between forward scatter and electronic sizing estimates of volume was demonstrated. After 75-min incubation, or every $15 \mathrm{~min}$ for $2 \mathrm{~h}, \sim 80 \mu \mathrm{l}$ sperm suspension $\left(\sim 2-10 \times 10^{6} \mathrm{sperm} / \mathrm{ml}\right)$ were added to $200 \mu \mathrm{l}$ of the same medium lacking BSA and containing $3 \mu \mathrm{l}$ propidium iodide (PI: $6 \mu \mathrm{g} / \mathrm{ml})$. Upon gentle agitation to mix the sample, flow cytometric measurements were recorded immediately. Forward and side scatter signals were recorded from laser excitation at $488 \mathrm{~nm}$. Data were collected from 5000 particles excluding cellular debris, gated out by forward and side scatter signals. Spermatozoa with ruptured membranes were gated out by the detection of PI fluorescence

Table 1 Major components of solutions (added to basal Biggers-Whittingham-Whitten (BWW)) used for the determination of sperm tonicity.

\begin{tabular}{lcccc}
\hline $\begin{array}{l}\text { Osmolality } \\
(\mathrm{mmol} / \mathrm{kg})\end{array}$ & $\begin{array}{c}\text { [Solute }] \\
(\mathrm{mM})\end{array}$ & {$\left[\mathbf{N a}^{+}\right](\mathrm{mM})$} & {$\left[\mathbf{C l}^{-}\right](\mathrm{mM})$} & $\begin{array}{c}\text { Ionic } \\
\text { strength }(\mu)\end{array}$ \\
\hline $\mathrm{NaCl}$ & & & & \\
340 & 120 & 171 & 128 & 0.189 \\
380 & 138 & 189 & 146 & 0.207 \\
420 & 168 & 219 & 176 & 0.237 \\
460 & 198 & 249 & 206 & 0.267 \\
500 & 222 & 273 & 230 & 0.291 \\
Choline & & & & \\
340 & 5 & 159 & 121 & 0.179 \\
380 & 30 & 159 & 146 & 0.192 \\
420 & 57 & 159 & 173 & 0.205 \\
460 & 84 & 159 & 200 & 0.219 \\
500 & 107 & 159 & 223 & 0.230 \\
Sucrose & & & & \\
340 & 10 & 159 & 116 & 0.177 \\
380 & 73 & 159 & 116 & 0.177 \\
420 & 135 & 159 & 116 & 0.177 \\
460 & 200 & 159 & 116 & 0.177 \\
500 & 253 & 159 & 116 & 0.177 \\
Lactose $^{\mathrm{a}}$ & & & & \\
340 & 10 & 159 & 116 & 0.177 \\
380 & 84 & 159 & 116 & 0.177 \\
420 & 158 & 159 & 116 & 0.177 \\
460 & 230 & 159 & 116 & 0.177 \\
500 & 159 & 116 & 0.177 \\
\hline
\end{tabular}

ancluding $108 \mathrm{mM} \mathrm{NaCl}$. 
(emission 605-635 nm). Mean values of forward scatter of the $\mathrm{Pl}$-negative cells were used for subsequent analysis. Because refractive index can alter forward scatter signals (Shapiro 1995), the forward scatter of standard beads was measured in every medium used and compared with that obtained in standard BWW330 to provide correction factors for all values generated from spermatozoa (mean \pm s.D., $0.988 \pm 0.020$ ).

\section{Determination of the tonicity of murine cauda epididymidal spermatozoa}

A method of null-point volume change was developed in which spermatozoa from the murine cauda epididymidis of C57BL6 strain mice were incubated in a range of osmolalities in the absence and presence of $0.8 \mathrm{mM}$ quinine. In hypotonic media, spermatozoa swell and initiate RVD; in the presence of quinine, this is inhibited and the cells remain swollen (Yeung et al. 2002a). In hypertonic media, spermatozoa will shrink; quinine can prevent RVI in lymphocytes (Grinstein et al. 1983) and porcine spermatozoa (Petrunkina et al. 2005), so spermatozoa remain shrunken. Thus, altering the osmolality of the medium from hypotonic to hypertonic should change the cell's response from swelling to shrinking: isotonicity was taken as that osmolality at which there was no change in sperm cell volume in response to quinine and was obtained by linear regression. For each of the four media, experiments were repeated on epididymal spermatozoa from four animals of the C57BL6 strain.

\section{Estimation of cell permeability at isotonicity}

At isotonicity (the absence of extracellular osmotic differences), no bulk water movement will occur, but osmotic entry of water can follow penetration of solutes and obliged water into the cell (Guizouarn \& Motais 1999). The extent of swelling will reflect the ease of entry of compounds provided at the same extracellular concentration. Compounds were added at a concentration of $250 \mathrm{mM}$ to basal BWW medium to achieve isotonicity (determined in the experiment above). The mean ( \pm s.D.) osmolality of these solutions was $533.7 \pm 11.0 \mathrm{mmol} / \mathrm{kg}$ $(n=39)$. Incubations were made at $37^{\circ} \mathrm{C}$ in $5 \%(v / v) \mathrm{CO}_{2}$ for $75 \mathrm{~min}$ in the absence and presence of $0.8 \mathrm{mM}$ quinine $\mathrm{HCl}$ (Sigma). Swelling under these iso-osmotic conditions indicates the diffusion of a permeant compound drawing in osmotically obliged water, and quinine sensitivity of the channels mediating influx would be revealed by different cell volumes in the presence and absence of the inhibitor. For most of the compounds tested, replicates were made on spermatozoa from six males; exceptions were trehalose $(n=4)$, fructose, dulcitol, THE, DMSO, EG $(n=5)$ and quinine $(n=72)$.

\section{Assessment of osmolyte load of cauda epididymidal spermatozoa from two strains of mice differing in post-thaw fertility}

For assessing the efficiency of sperm response to osmotic challenge, the basal BWW medium (see above) was modified to create a series of solutions of increasing osmolality (160-530 mmol $/ \mathrm{kg}$ ) containing a) 6.25, 108, $227 \mathrm{mM} \mathrm{NaCl}$ or b) $2.5,93,172,322 \mathrm{mM}$ sucrose replacing the $108 \mathrm{mM}$
Table 2 Major components of solutions used for the determination of sperm osmolyte load.

\begin{tabular}{lcccc}
\hline $\begin{array}{l}\text { Osmolality } \\
(\mathrm{mmol} / \mathrm{kg})\end{array}$ & $\begin{array}{c}\text { [Solute }] \\
(\mathrm{mM})\end{array}$ & {$\left[\mathrm{Na}^{+}\right](\mathrm{mM})$} & {$\left[\mathbf{C l}^{-}\right](\mathrm{mM})$} & $\begin{array}{c}\text { Ionic } \\
\text { strength }(\mu)\end{array}$ \\
\hline $\mathrm{NaCl}$ & & & & \\
530 & 227 & 278 & 235 & 0.296 \\
330 & 108 & 159 & 116 & 0.177 \\
245 & 6.3 & 58 & 14 & 0.075 \\
160 & 0.1 & 51 & 8 & 0.069 \\
$\mathrm{Na}-$ gluconate & & & & \\
330 & 0 & 159 & 116 & 0.177 \\
330 & 58 & 159 & 58 & 0.177 \\
330 & 87 & 159 & 29 & 0.177 \\
330 & 101 & 159 & 15 & 0.177 \\
Sucrose & & & & \\
530 & 322 & 65 & 22 & 0.083 \\
330 & 172 & 65 & 22 & 0.083 \\
245 & 93 & 65 & 22 & 0.083 \\
160 & 2.5 & 65 & 22 & 0.083 \\
\hline
\end{tabular}

$\mathrm{NaCl}$ in basal BWW. To evaluate the effect of $\mathrm{Cl}$, the $\mathrm{NaCl}$ content of the basal BWW $(330 \mathrm{mmol} / \mathrm{kg}$ ) was replaced with $\mathrm{Na}^{+}$-gluconate. The $\mathrm{Na}^{+}$and $\mathrm{Cl}^{-}$concentrations and ionic strengths of these media are given in Table 2. Volume responses of Pl-intact cells were monitored with time for spermatozoa that differ in susceptibility to cryodamage. They were from two strains of mice: B6D2F with high and C57BL6 with low postthaw fertilisation rates (Songsasen \& Leibo 1997). The extent of RVD in each of the nine solutions was repeated on spermatozoa from six males of each strain.

\section{Statistical analysis}

Null points were determined by linear regression analysis. Effects of quinine on penetration and the size differences at different osmolalities were examined by paired $t$-tests. Significant changes in size were tested with one-way ANOVA (performed on Ranks when not normally distributed or with unequal variance). Comparisons between mouse strains with time were made with two-way ANOVA (SigmaStat). Significant differences were accepted when $P<0.05$.

\section{Acknowledgements}

J P B was supported by a Crescent City doctoral scholarship from the University of New Orleans. The research was supported by the Schering Research Foundation - CONRAD AMPPAII Research Network. The authors declare that there is no conflict of interest that would prejudice the impartiality of this scientific work.

\section{References}

Agca Y, Gilmore J, Byers M, Woods EJ, Liu J \& Critser JK 2002 Osmotic characteristics of mouse spermatozoa in the presence of extenders and sugars. Biology of Reproduction 67 1493-1501.

Barfield JP, Yeung CH \& Cooper TG 2005 The effects of putative $\mathrm{K}^{+}$channel blockers on volume regulation of murine spermatozoa. Biology of Reproduction 72 1275-1281. 
Biggers JD, Whittem WK \& Whittingham DG 1971 The culture of mouse embryos in vitro. In Methods in Mammalian Embryology, pp 86-116. Ed. JC Daniel. San Francisco: Freeman.

Cooper TG 1998 In Encyclopedia of Reproduction, pp 1-17. Eds JD Neill \& E Knobil. San Diego: Academic Press.

Cooper TG \& Barfield JP 2006 Utility of infertile male models for contraception and conservation. Molecular and Cellular Endocrinology $250206-211$.

Cooper TG \& Yeung CH 2003 Acquisition of volume regulatory response of sperm upon maturation in the epididymis and the role of cytoplasmic droplets. Microscopy Research and Technique 61 28-38.

Cooper TG, Yeung $\mathrm{CH}$, Wagenfeld A, Nieschlag E, Poutanen M, Huhtaniemi I \& Sipilä P 2004 Mouse models of infertility due to swollen spermatozoa. Molecular and Cellular Endocrinology 216 55-63.

Drevius LO 1971 Permeability coefficients of bull spermatozoa for water and polyhydric alcohols. Experimental Cell Research 69 212-216.

Drevius LO 1972 The permeability of bull spermatozoa to water, polyhydric alcohols and univalent anions and the effects of the anions upon the kinetic activity of spermatozoa and sperm models. Journal of Reproduction and Fertility 28 41-54.

Du J, Tao J, Kleinhans FW, Mazur P \& Critser JK 1994 Water volume and osmotic behaviour of mouse spermatozoa determined by electron paramagnetic resonance. Journal of Reproduction and Fertility $10137-42$.

Gao DY, Liu J, Liu C, McGann LE, Watson P, Kleihans FW, Mazur P, Critser ES \& Critser JK 1995 Prevention of osmotic injury to human spermatozoa during addition and removal of glycerol. Human Reproduction 10 1109-1122.

Gao D, Mazur P \& Critser JK 1997 Fundamental cryobiology of mammalian spermatozoa. In Reproductive Tissue Banking, pp 263-328. Eds AM Karow \& JW Critser. San Diego: Academic Press.

Grinstein S, Clarke CA \& Rothstein A 1983 Activation of $\mathrm{Na}^{+} / \mathrm{H}^{+}$ exchange in lymphocytes by osmotically induced volume changes and by cytoplasmic acidification. Journal of General Physiology 82 619-638.

Guizouarn H \& Motais R 1999 Swelling activation of transport pathways in erythrocytes: effects of $\mathrm{Cl}^{-}$, ionic strength, and volume changes. American Journal of Physiology 276 C210-C220.

Joost HG \& Thorens B 2001 The extended GLUT-family of sugar/polyol transport facilitators: nomenclature, sequence characteristics, and potential function of its novel members (review). Molecular Membrane Biology 18 247-256.

Knaus HG, Koch RO, Eberhart A, Kaczorowski GJ, Garcia ML \& Slaughter RS 1995 [ ${ }^{125}$ I]margatoxin, an extraordinarily high affinity ligand for voltage-gated potassium channels in mammalian brain. Biochemistry 34 13627-13634.

Kulkarni SB, Sauna ZE, Somlata V \& Sitaramam V 1997 Volume regulation of spermatozoa by quinine-sensitive channels. Molecular Reproduction and Development 46 535-550.

Leibo S \& Bradley L 1999 Comparative cryobiology of mammalian spermatozoa. In The Male Gamete. From Basic Science to Clinical Applications, pp 502-516. Ed. C Gagnon. Vienna, USA: Cache River Press.

Leibo SP, Picton HM \& Gosden RG 2002 Cryopreservation of human spermatozoa. In Current Practices and Controversies in Assisted Reproduction, pp 152-165. Eds E Vayena, PJ Rowe \& PD Griffin. Geneva: WHO.

McLaughlin EA, Ford WCL \& Hull MRG 1992 Motility characteristics and membrane integrity of cryopreserved human spermatozoa. Reproduction, Fertility, and Development 95 5527-5534.

Nilius B, Eggermont J \& Droogmans G 2000 The endothelial volume-regulated anion channel, VRAC. Cellular Physiology and Biochemistry 10 313-320.

Noiles EE, Bailey JL \& Storey BT 1995 The temperature dependence in the hydraulic conductivity, $L_{p}$, of the mouse sperm plasma membrane shows a discontinuity between 4 and $0{ }^{\circ} \mathrm{C}$. Cryobiology 32 220-238.

Noiles EE, Thompson KA \& Storey BT 1997 Water permeability, $L_{p}$, of the mouse sperm plasma membrane and its activation energy are strongly dependent on interaction of the plasma membrane with sperm cytoskeleton. Cryobiology 35 79-92.

Petrunkina AM, Jebe E \& Töpfer-Petersen E 2005 Regulator and necrotic volume increase in boar spermatozoa. Journal of Cellular Physiology 204 508-521.

Phelps MJ, Liu J, Benson JD, Willoughby CE, Gilmore JA \& Critser JK 1999 Effects of Percoll separation, cryoprotective agents, and temperature on plasma membrane permeability characteristics of murine spermatozoa and their relevance to cryopreservation. Biology of Reproduction $\mathbf{6 1}$ 1031-1041.
Phillips DM \& Kalay D 1984 Mechanisms of flagellar motility deduced from backward-swimming bull sperm. Journal of Experimental Zoology 231 109-116.

Rigau T, Rivera M, Palomo MJ, Fernandez-Novell JM, Mogas T, Ballester J, Pena A, Otaegui PJ, Guinovart JJ \& Rodriguez-Gil J 2002 Differential effects of glucose and fructose on hexose metabolism in dog spermatozoa. Reproduction 123 579-591.

Sabirov RZ, Prenen J, Tomita T, Droogmans G \& Nilius B 2000 Reduction of ionic strength activates single volume-regulated anion channels (VRAC) in endothelial cells. Pflugers Archiv 439 315-320.

Salisbury GW \& Cragle RG 1956 Freezing-point depressions and mineral levels of fluids of the ruminant male reproductive tract. Proceedings of the IIIrd International Congress on Animal Reproduction, Cambridge. 25-28.

Shapiro HM 1995 In Practical Flow Cytometry, pp 231-232. New York: Wiley-Liss.

Songsasen N \& Leibo SP 1997 Cryopreservation of mouse spermatozoa. II. Relationship between survival after cryopreservation and osmotic tolerance of spermatozoa from three strains of mice. Cryobiology 35 255-269.

Storey BT, Noiles EE \& Thompson KA 1998 Comparison of glycerol, other polyols, trehalose, and raffinose to provide a defined cryoprotectant medium for mouse sperm cryopreservation. Cryobiology 37 46-58.

Strange K \& Jackson PS 1995 Swelling-activated organic osmolyte efflux: a new role for anion channels. Kidney International 48 994-1003.

Tsukaguchi H, Shayakul C, Berger UV, Mackenzie B, Devidas S, Guggino WB, van Hoek AN \& Hediger MA 1998 Molecular characterization of a broad selectivity neutral solute channel. Journal of Biological Chemistry 273 24737-24743.

Verbeckmoes S, De Pauw I, Van Soom A \& de Krief A 2001 lonic composition and osmolarity of caudal epididymal plasma in the bull. Theriogenology 55449.

Walters EM, Men H, Agca Y, Mullen SF, Critser ES \& Critser JK 2005 Osmotic tolerance of mouse spermatozoa from various genetic backgrounds: acrosome integrity, membrane integrity, and maintenance of motility. Cryobiology $\mathbf{5 0}$ 193-205.

White IG \& Macleod J 1963 Composition and physiology of semen. In Mechanisms Concerned With Conception, pp 135-172. Ed. CG Hartman. Oxford: Pergamon.

Willoughby CE, Mazur P, Peter AT \& Critser JK 1996 Osmotic tolerance limits and properties of murine spermatozoa. Biology of Reproduction $\mathbf{5 5}$ 715-727.

Yeung CH, Sonnenberg-Riethmacher E \& Cooper TG 1999 Infertile spermatozoa of c-ros tyrosine kinase receptor knockout mice show flagellar angulation and maturational defects in cell volume regulatory mechanisms. Biology of Reproduction 61 1062-1069.

Yeung CH, Wagenfeld A, Nieschlag E \& Cooper TG 2000 The cause of infertility of male c-ros tyrosine kinase receptor knockout mice. Biology of Reproduction 63 612-618.

Yeung CH, Anapolski M, Sipilä P, Wagenfeld A, Poutanen M, Huhtaniemi I, Nieschlag E \& Cooper TG 2002 a Sperm volume regulation: maturational changes in fertile and infertile transgenic mice and association with kinematics and tail angulation. Biology of Reproduction 67 269-275.

Yeung CH, Anapolski M \& Cooper TG 2002b Measurement of volume changes in mouse spermatozoa using an electronic sizing analyzer and a flow cytometer: validation and application to an infertile mouse model. Journal of Andrology 23 522-528.

Yeung CH, Anapolski M, Setiawan I, Lang F \& Cooper TG 2004 Effects of putative epididymal osmolytes on sperm volume regulation of fertile and infertile c-ros transgenic mice. Journal of Andrology 25 216-223.

Yu I, Songsasen N, Godke RA \& Leibo SP 2002 Differences among dogs in response of their spermatozoa to cryopreservation using various cooling and warming rates. Cryobiology 44 62-78.

Zablocki K, Miller SP, Garcia-Perez A \& Burg MB 1991 Accumulation of glycerophosphocholine (GPC) by renal cells: osmotic regulation of GPC:choline phosphodiesterase. PNAS 88 7820-7824.

Received 21 December 2007

First decision 22 January 2008

Revised manuscript received 12 February 2008

Accepted 18 February 2008 